\title{
The effects of grounding (earthing) on inflammation, the immune response, wound healing, and prevention and treatment of chronic inflammatory and autoimmune diseases
}

\author{
This article was published in the following Dove Press journal: \\ Journal of Inflammation Research \\ 24 March 2015 \\ Number of times this article has been viewed
}

\section{James L Oschman' \\ Gaétan Chevalier ${ }^{2}$ \\ Richard Brown ${ }^{3}$}

'Nature's Own Research Association, Dover, NH, USA; '2Developmental and Cell Biology Department, University of California at Irvine, Irvine, CA, USA; ${ }^{3}$ Human Physiology Department, University of Oregon, Eugene, OR, USA
Correspondence: Gaétan Chevalier Developmental and Cell Biology Department, University of California at Irvine, 2103 McGaugh Hall, Irvine, CA, 92697-2300, USA

$\mathrm{Tel}+\mathrm{I} 760815927 \mid$

$\mathrm{Fax}+\mathrm{I} 8582253514$

Email dlbogc@sbcglobal.net

\begin{abstract}
Multi-disciplinary research has revealed that electrically conductive contact of the human body with the surface of the Earth (grounding or earthing) produces intriguing effects on physiology and health. Such effects relate to inflammation, immune responses, wound healing, and prevention and treatment of chronic inflammatory and autoimmune diseases. The purpose of this report is two-fold: to 1) inform researchers about what appears to be a new perspective to the study of inflammation, and 2) alert researchers that the length of time and degree (resistance to ground) of grounding of experimental animals is an important but usually overlooked factor that can influence outcomes of studies of inflammation, wound healing, and tumorigenesis. Specifically, grounding an organism produces measurable differences in the concentrations of white blood cells, cytokines, and other molecules involved in the inflammatory response. We present several hypotheses to explain observed effects, based on current research results and our understanding of the electronic aspects of cell and tissue physiology, cell biology, biophysics, and biochemistry. An experimental injury to muscles, known as delayed onset muscle soreness, has been used to monitor the immune response under grounded versus ungrounded conditions. Grounding reduces pain and alters the numbers of circulating neutrophils and lymphocytes, and also affects various circulating chemical factors related to inflammation.
\end{abstract}

Keywords: chronic inflammation, immune system, wound repair, white blood cells, macrophages, autoimmune disorders

\section{Introduction}

Grounding or earthing refers to direct skin contact with the surface of the Earth, such as with bare feet or hands, or with various grounding systems. Subjective reports that walking barefoot on the Earth enhances health and provides feelings of well-being can be found in the literature and practices of diverse cultures from around the world. ${ }^{1}$ For a variety of reasons, many individuals are reluctant to walk outside barefoot, unless they are on holiday at the beach. Experience and measurements show that sustained contact with the Earth yields sustained benefits. Various grounding systems are available that enable frequent contact with the Earth, such as while sleeping, sitting at a computer, or walking outdoors. These are simple conductive systems in the form of sheets, mats, wrist or ankle bands, adhesive patches that can be used inside the home or office, and footwear. These applications are connected to the Earth via a cord inserted into a grounded wall outlet or attached to a ground rod placed in the soil outside below a window. For the footwear applications, a conductive plug is positioned in 
the shoe sole at the ball of the foot, under the metatarsals, at the acupuncture point known as Kidney 1. From a practical standpoint, these methods offer a convenient and routine, user-friendly approach to grounding or earthing. They can also be used in clinical situations, as will be described in the section entitled Summary of findings to date. ${ }^{1}$

Recently, a group of about a dozen researchers (including the authors of this paper) has been studying the physiological effects of grounding from a variety of perspectives. This research has led to more than a dozen studies published in peer-reviewed journals. While most of these pilot studies involved relatively few subjects, taken together, the research has opened a new and promising frontier in inflammation research, with broad implications for prevention and public health. The findings merit consideration by the inflammation research community, which has the means to verify, refute, or clarify the interpretations we have made thus far.

Grounding reduces or even prevents the cardinal signs of inflammation following injury: redness, heat, swelling, pain, and loss of function (Figures 1 and 2). Rapid resolution of painful chronic inflammation was confirmed in 20 case studies using medical infrared imaging (Figure 3). ${ }^{2,3}$

Our main hypothesis is that connecting the body to the Earth enables free electrons from the Earth's surface to spread over and into the body, where they can have antioxidant effects. Specifically, we suggest that mobile electrons create an antioxidant microenvironment around the injury repair field, slowing or preventing reactive oxygen species (ROS) delivered by the oxidative burst from causing "collateral damage" to healthy tissue, and preventing or reducing the formation of the so-called "inflammatory barricade". We also hypothesize that electrons from the Earth can prevent or resolve so-called "silent" or "smoldering" inflammation. If verified, these concepts may help us better understand and research the inflammatory response and wound healing, and develop new information on how the immune system functions in health and disease.

\section{Summary of findings to date}

Grounding appears to improve sleep, normalize the day-night cortisol rhythm, reduce pain, reduce stress, shift the autonomic nervous system from sympathetic toward parasympathetic activation, increase heart rate variability, speed wound healing, and reduce blood viscosity. A summary has been published in the Journal of Environmental and Public Health. ${ }^{4}$

\section{Effects on sleep}

One of the first published grounding studies examined the effects of grounding on sleep and circadian cortisol profiles. ${ }^{5}$
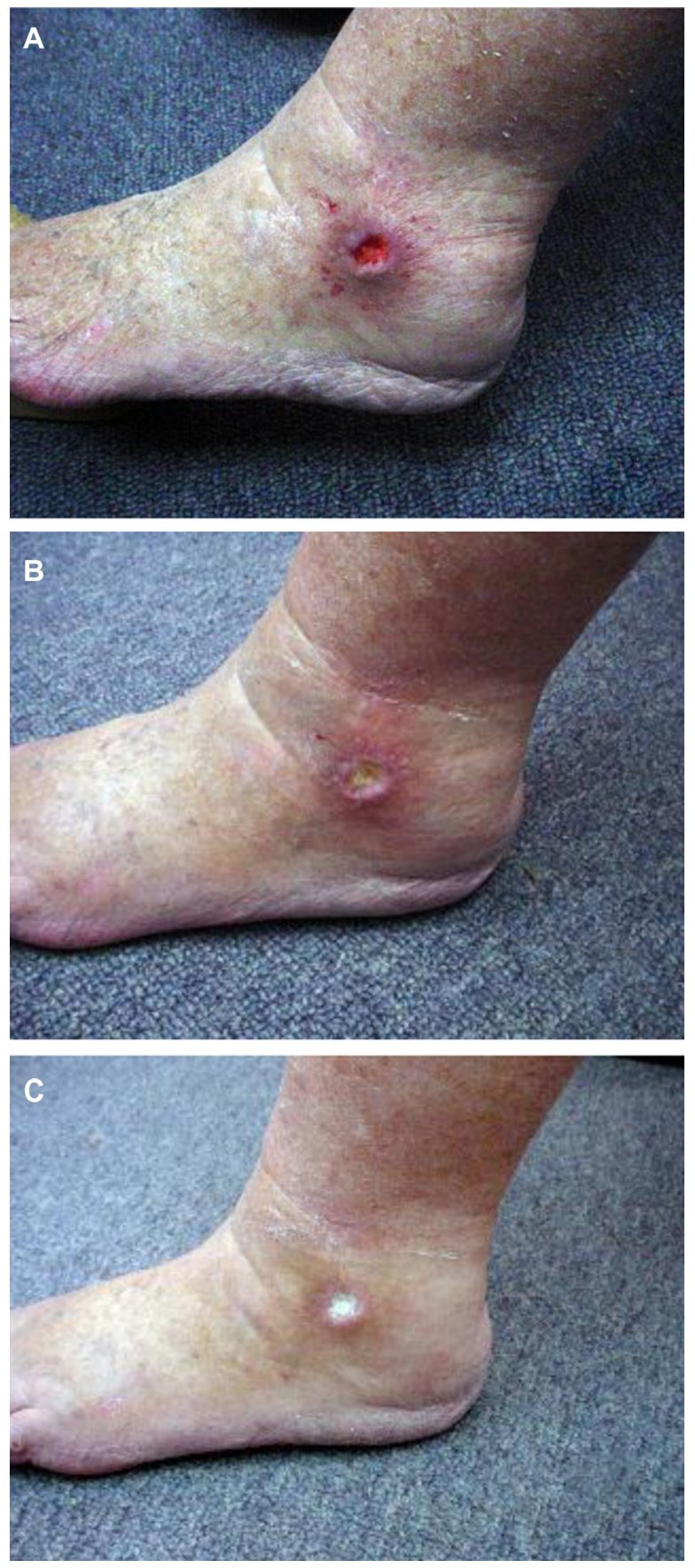

Figure I Photographic images documenting accelerated improvement of an 8-monthold, non-healing open wound suffered by an 84-year-old diabetic woman.

Notes: (A) Shows the open wound and a pale-gray hue to the skin. (B) Taken after one week of grounding or earthing treatments, shows a marked level of healing and improvement in circulation, as indicated by the skin color. (C) Taken after 2 weeks of earthing treatment, shows the wound healed over and the skin color looking dramatically healthier. Treatment consisted of a daily 30-minute grounding session with an electrode patch while patient was seated comfortably. The cause of the wound adjacent to the left ankle was a poorly fitted boot. A few hours after wearing the boot, a blister formed, and then developed into a resistant open wound. The patient had undergone various treatments at a specialized wound center with no improvement. Vascular imaging of her lower extremities revealed poor circulation. When first seen, she had a mild limp and was in pain. After an initial 30 minutes of exposure to grounding, the patient reported a noticeable decrease in pain. After I week of daily grounding, she said her pain level was about $80 \%$ less. At that time, she showed no evidence of a limp. At the end of 2 weeks, she said she was completely pain-free. 

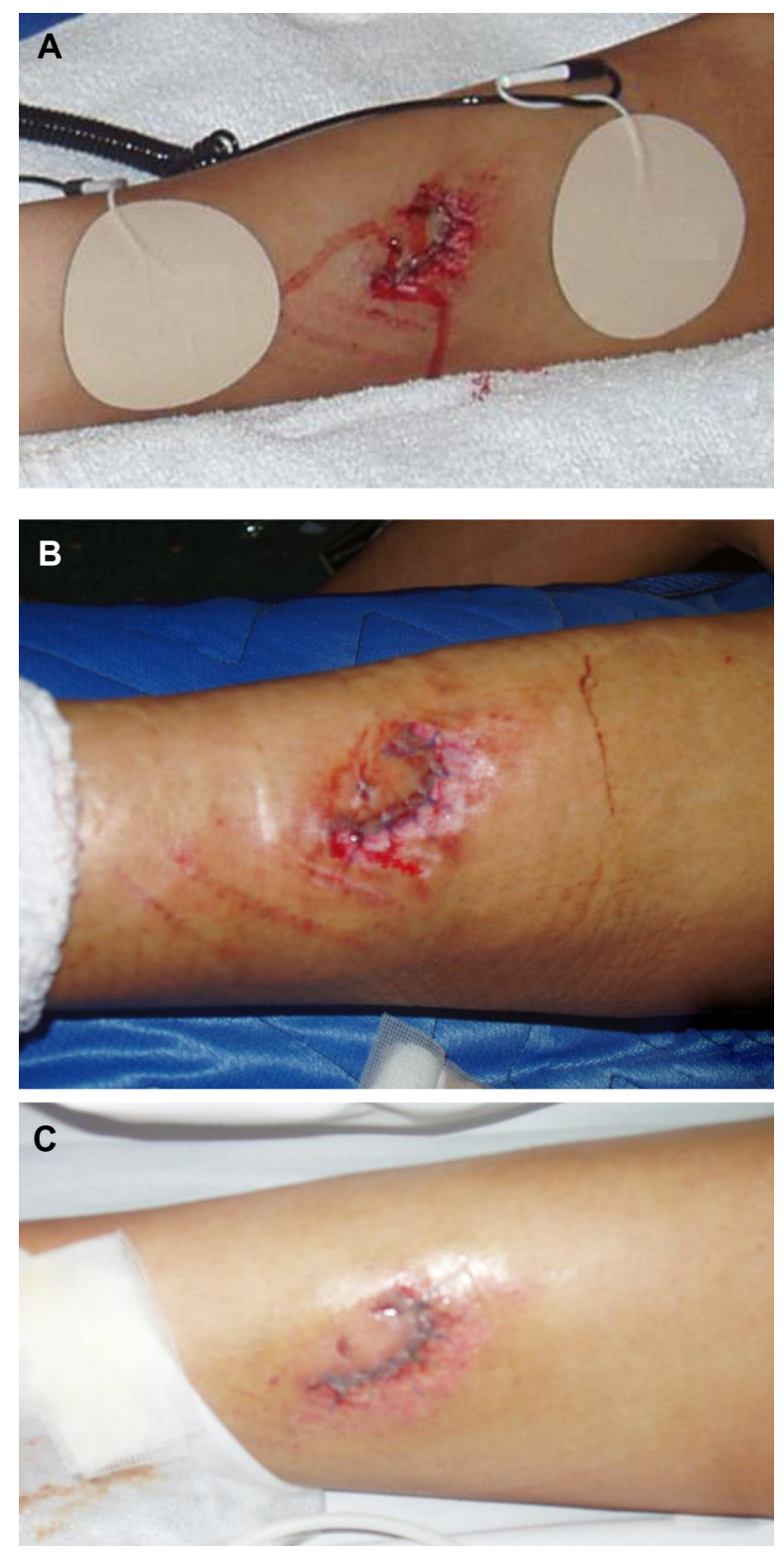

Figure 2 Rapid recovery from a serious wound with minimal swelling and redness expected for such a serious injury.

Notes: Cyclist was injured in Tour de France competition - chain wheel gouged his leg. (A) Grounding patches were placed above and below wound as soon as possible after injury. Photo courtesy of Dr Jeff Spencer. (B) Day I after injury. (C) Day 2 after injury. There was minimal redness, pain, and swelling, and cyclist was able to continue the race on the day following the injury. (B and C) Copyright (C) 2014. Reprinted with permission from Basic Health Publications, Inc. Ober CA, Sinatra ST, Zucker M. Earthing: The Most Important Health Discovery Ever? 2nd ed. Laguna Beach: Basic Health Publications; 2014.'

The study involved 12 subjects who were in pain and had problems sleeping. They slept grounded for 8 weeks using the system shown in Figure 4. During this period, their diurnal cortisol profiles normalized, and most of the subjects reported that their sleep improved and their pain and stress levels declined.

The results of the experiment led to these conclusions: 1) grounding the body during sleep yields quantifiable changes in diurnal or circadian cortisol secretion levels that, in turn, 2) produce changes in sleep, pain, and stress (anxiety, depression, and irritability), as measured by subjective reporting. The cortisol effects described by Ghaly and Teplitz ${ }^{5}$ are particularly significant in the light of recent research showing that prolonged chronic stress results in glucocorticoid receptor resistance. ${ }^{6}$ Such resistance results in failure to downregulate inflammatory responses, which can thereby increase risks of a variety of chronic diseases. This effect complements the findings described in the "Effects on pain and the immune response" section.

\section{Effects on pain and the immune response}

A pilot study on the effects of grounding on pain and the immune response to injury employed delayed-onset muscle soreness (DOMS). ${ }^{7}$ DOMS is the muscular pain and stiffness that takes place hours to days after strenuous and unfamiliar exercise. DOMS is widely used as a research model by exercise and sports physiologists. The soreness of DOMS is caused by temporary muscle damage produced by eccentric exercise. The phase of contraction that occurs when a muscle shortens, as in lifting a dumbbell, is referred to as concentric, whereas the phase of contraction as a muscle lengthens, as in lowering a dumbbell, is referred to as eccentric.

Eight healthy subjects performed an unfamiliar, eccentric exercise that led to pain in their gastrocnemius muscles. This was done by having them perform two sets of 20 toe raises with a barbell on their shoulders and the balls of their feet on a 2 -inch $\times 4$-inch wooden board. ${ }^{7}$

All subjects ate standardized meals at the same time of day, and adhered to the same sleep cycle for 3 days. At $5.40 \mathrm{pm}$ on each day, four of the subjects had conductive grounding patches adhered to their gastrocnemius muscles and the bottoms of their feet. They rested and slept on grounding systems such as that shown in Figure 4. They remained on the grounded sheets except for visits to the bathroom and meals. As controls, four subjects followed the same protocol except that their patches and sheets were not grounded. The following measurements were taken before the exercise and 1,2 , and 3 days thereafter: pain levels, magnetic resonance imaging, spectroscopy, cortisol in serum and saliva, blood and enzyme chemistry, and blood cell counts. ${ }^{7}$

Pain was monitored with two techniques. The subjective method involved morning and afternoon use of a Visual Analog Scale. In the afternoon, a blood pressure cuff was positioned on the right gastrocnemius and inflated to the point of acute discomfort. The pain was documented in terms of the highest pressures that could be tolerated. The grounded subjects experienced less pain, as revealed with 

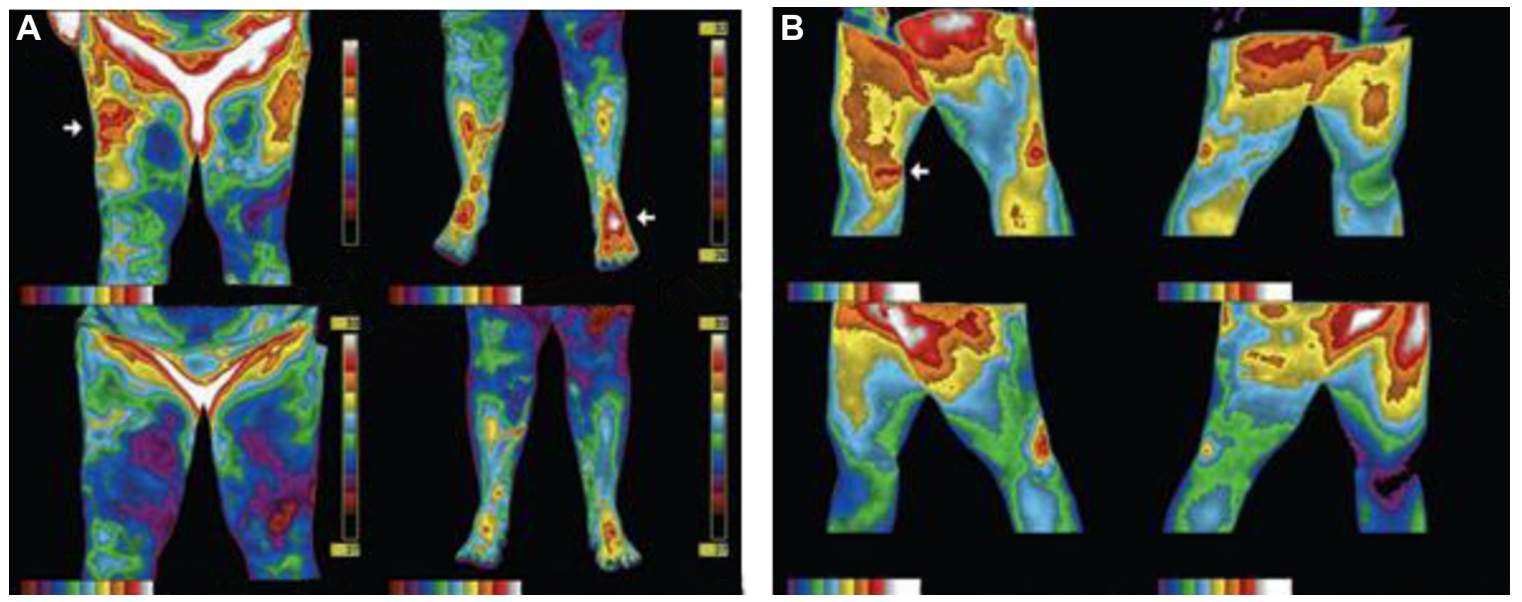

Figure 3 Reduction in inflammation with grounding or earthing documented with medical infrared imaging.

Notes: Thermal imaging cameras record tiny changes in skin temperature to create a color-coded map of hot areas indicative of inflammation. Panel $\mathbf{A}$ shows reduction in inflammation from sleeping grounded. Medical infrared imaging shows warm and painful areas (arrows in upper part of panel A). Sleeping grounded for 4 nights resolved the pain, and the hot areas cooled. Note the significant reduction in inflammation and a return toward normal thermal symmetry. Panel B shows infrared images of a 33-year-old woman who had a gymnastics injury at age 15. The patient had a long history of chronic right knee pain, swelling, and instability, and was unable to stand for long periods. Simple actions, such as driving, increased the symptoms. She had to sleep with a pillow between her knees to decrease the pain. On-and-off medical treatment and physical therapy over the years provided minimal relief. She presented on November 17, 2004 with considerable right medial knee tenderness and a mild limp. Top images in Panel B were taken in walking position to show the inside of both knees. Arrow points to exact location of patient's pain and shows significant inflammation. Lower images in Panel $\mathbf{B}$ taken 30 minutes after being grounded with an electrode patch. The patient reported a mild reduction in pain. Note significant reduction of inflammation in knee area. After 6 days of grounding, she reported a $50 \%$ reduction pain and said that she could now stand for longer periods without pain, and no longer needed to sleep with pillow between her legs. After 4 weeks of treatment, she felt good enough to play soccer, and for the first time in 15 years felt no instability and little pain. By 12 weeks, she said her pain had diminished by nearly $90 \%$ and she had no swelling. For the first time in many years, she was able waterski. The patient contacted the office after 6 months of treatment to report that she had finished a half-marathon, something she never dreamt she would ever be able to do prior to treatment.

both the analog soreness scale (Figure 5) and by their ability to tolerate a higher pressure from the blood pressure cuff (Figure 6). ${ }^{7}$

The DOMS grounding study report ${ }^{7}$ contains a summary of the literature on the changes in blood chemistry and content of formed elements (erythrocytes, leukocytes, and platelets) expected after an injury. The immune system detects pathogens

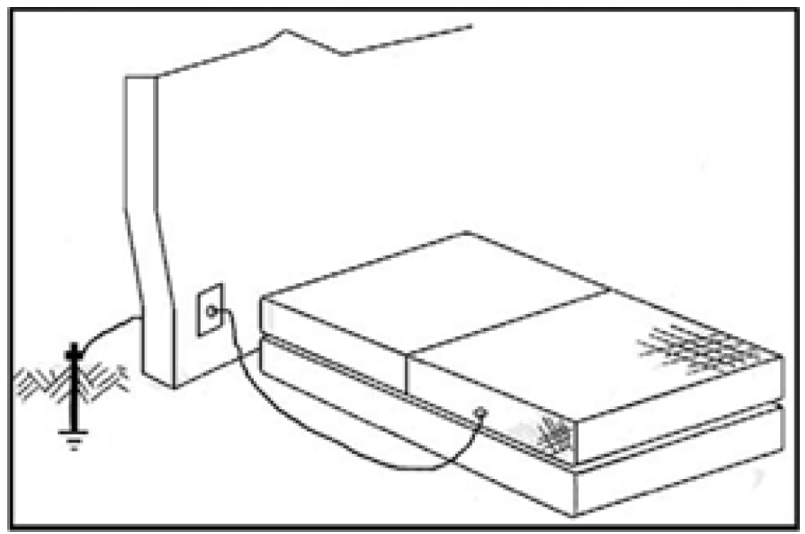

Figure 4 Grounded sleep system.

Notes: Grounded sleep system consists of a cotton sheet with conductive carbon or silver threads woven into it. The threads connect to a wire that leads out the bedroom window or through the wall to a metal rod inserted into the Earth near a healthy plant. Alternatively, it can be connected to the ground terminal of an electrical outlet. Sleeping on this system connects the body to the Earth. A frequent report from people using this system is that sleeping grounded improves the quality of sleep and reduces aches and pains from a variety of causes. and tissue damage and responds by initiating the inflammation cascade, sending neutrophils and lymphocytes into the region. ${ }^{8-12}$ As expected, the white cell counts increased in the ungrounded or control subjects. White cell counts in the grounded subjects steadily decreased following the injury (Figure 7). ${ }^{7}$

Previous research has shown increases in neutrophils following injury. ${ }^{13-16}$ This happened in both grounded and ungrounded subjects (Figure 8), although neutrophil counts were always lower in the grounded subjects. ${ }^{7}$

As the number of neutrophils increases, lymphocytes are expected to decrease. ${ }^{17-19}$ In the DOMS study, the lymphocyte count in the grounded subjects was always below the ungrounded subjects (Figure 9). ${ }^{7}$

Normally, neutrophils rapidly invade an injured region $^{8,20-22}$ in order to break down damaged cells and send signals through the cytokine network to regulate the repair process. Neutrophils' production of ROS and reactive nitrogen species (RNS) is termed the "oxidative burst". ${ }^{21}$ While ROS clear pathogens and cellular debris so that the tissue can regenerate, ROS can also damage healthy cells adjacent to the repair field, causing so-called collateral damage. The fact that the grounded subjects had fewer circulating neutrophils and lymphocytes could indicate that the original damage resolved more quickly, collateral damage reduced, and the recovery process accelerated. This would explain the reduction in the 

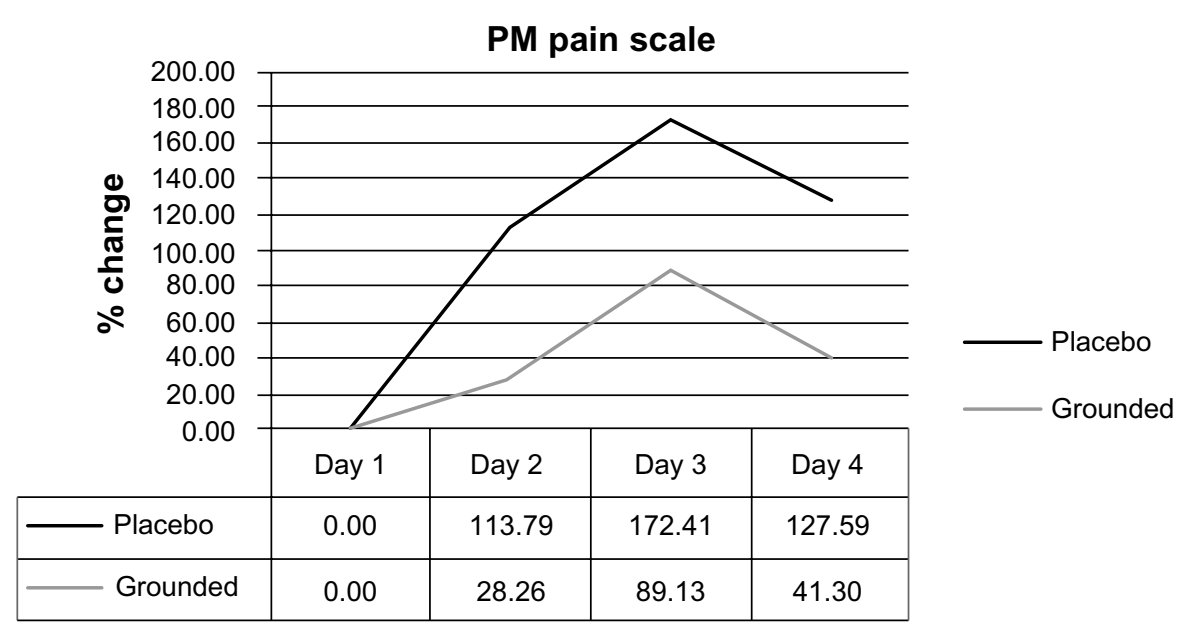

Figure 5 Changes in afternoon (PM) visual analog pain scale reports.

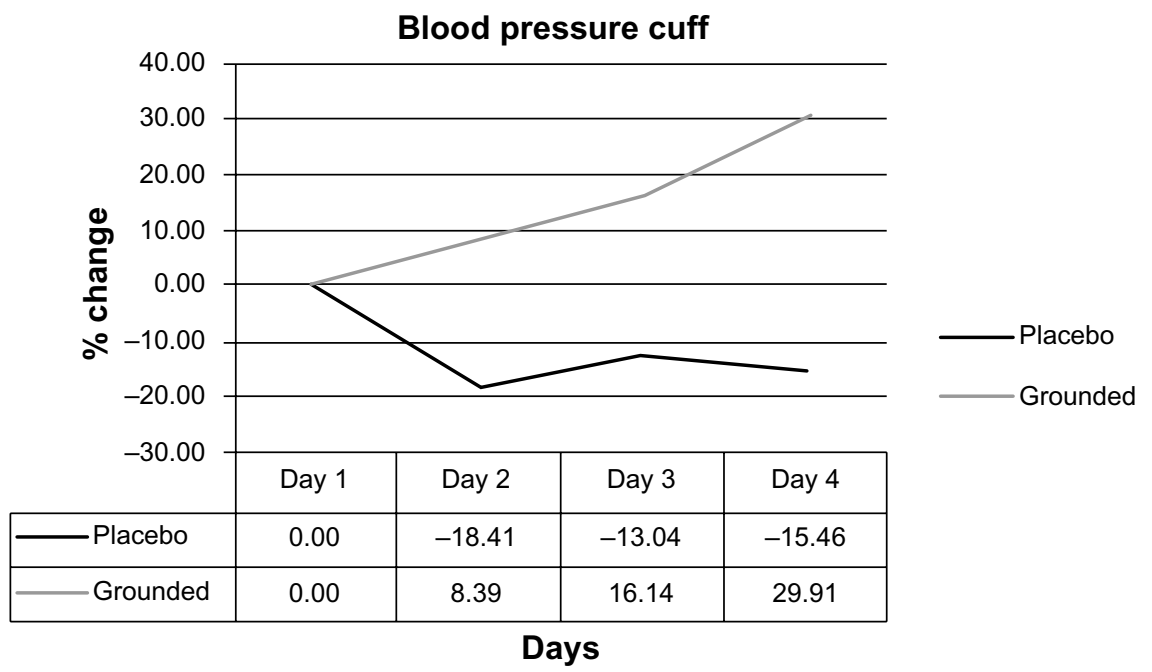

Figure 6 Changes in afternoon (PM) pain levels using a blood pressure cuff.

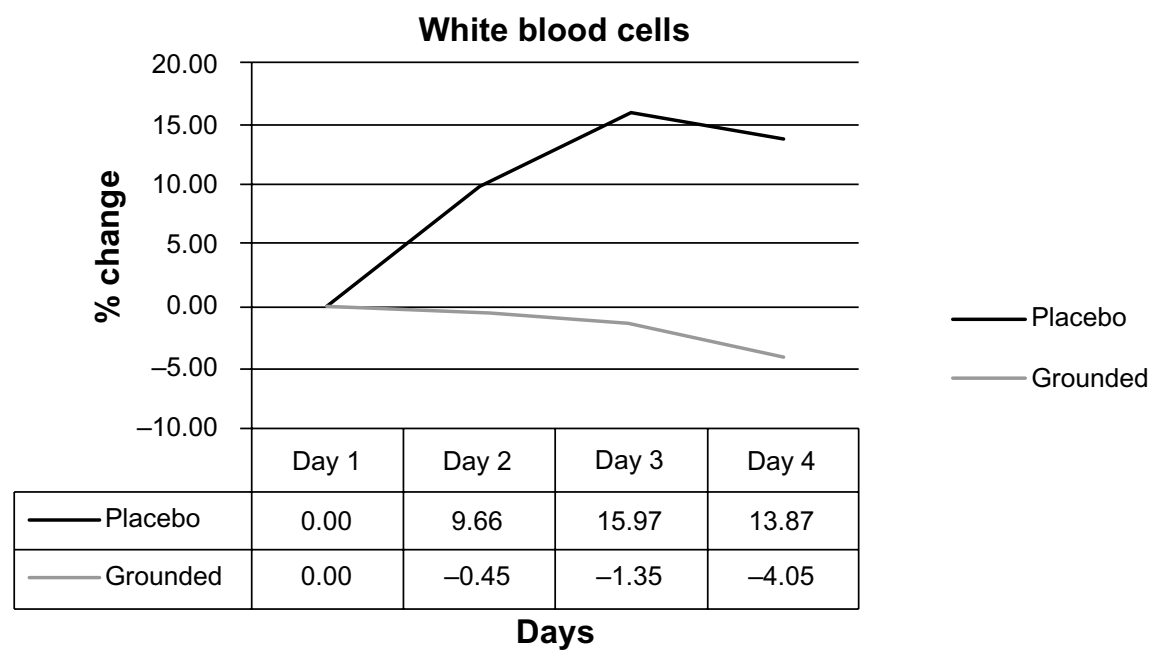

Figure 7 Comparisons of white blood cell counts, comparing pretest versus post-test for each group. 


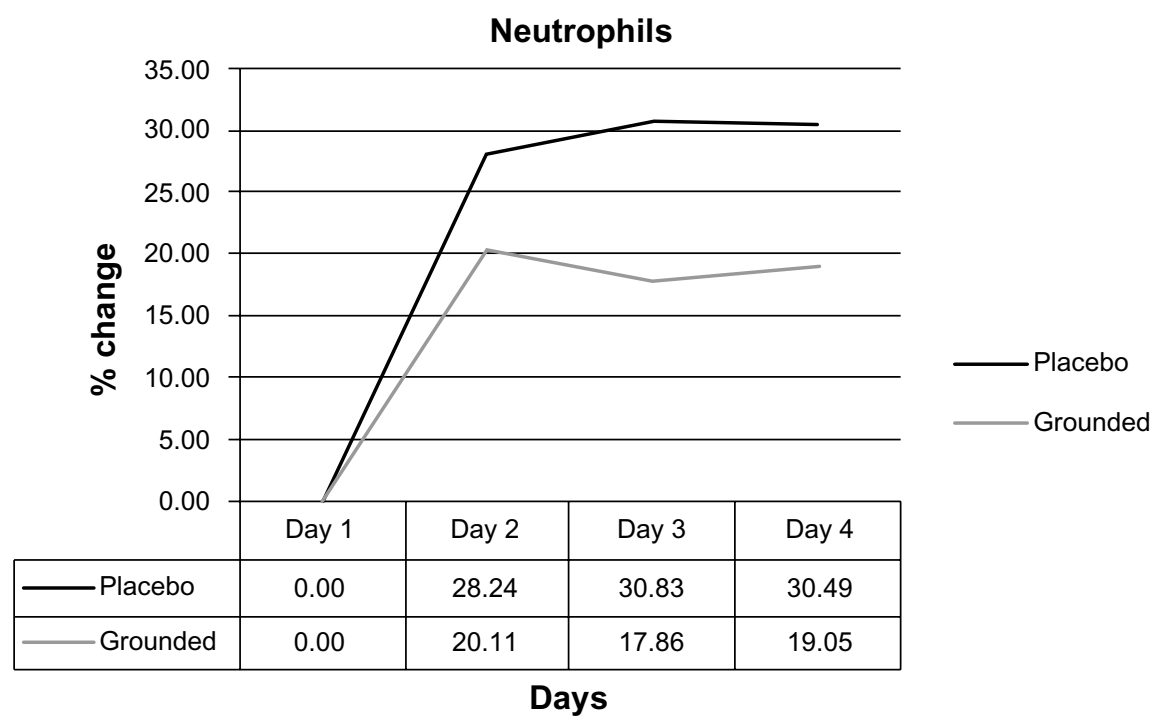

Figure 8 Comparisons of neutrophil counts, pretest versus post-test for each group.

cardinal signs of inflammation (redness, heat, swelling, pain, and loss of function) following acute injury, as documented, for example, in Figures 1 and 2, and the rapid reduction of chronic inflammation documented in Figure 3.

Our working hypothesis features this scenario: mobile electrons from the Earth enter the body and act as natural antioxidants; ${ }^{3}$ they are semi-conducted through the connective tissue matrix, including through the inflammatory barricade if one is present; ${ }^{23}$ they neutralize ROS and other oxidants in the repair field; and they protect healthy tissue from damage. The fact that there are fewer circulating neutrophils and lymphocytes in the grounded subjects may be advantageous because of the harmful role these cells are thought to play in prolonging inflammation. ${ }^{24}$ We also raise the possibility that the inflammatory barricade is actually formed in ungrounded subjects by collateral damage to healthy tissue, as was suggested by Selye in the first and subsequent editions of his book The Stress of Life (Figure 10). ${ }^{25}$

While there may be other explanations, we suggest that rapid resolution of inflammation takes place because the Earth's surface is an abundant source of excited and mobile electrons, as described in our other work. ${ }^{1}$ We further propose that skin contact with the surface of the Earth allows Earth's electrons to spread over the skin surface and into the body. One route to the body interior could be via acupuncture points and meridians. The meridians are known to be low resistance pathways for the flow of electrical currents. ${ }^{26-28}$ Another pathway is via mucous membranes of the respiratory and digestive tracts, which are continuous with the skin surface. Sokal and Sokal ${ }^{29}$ found that the electrical potential on the

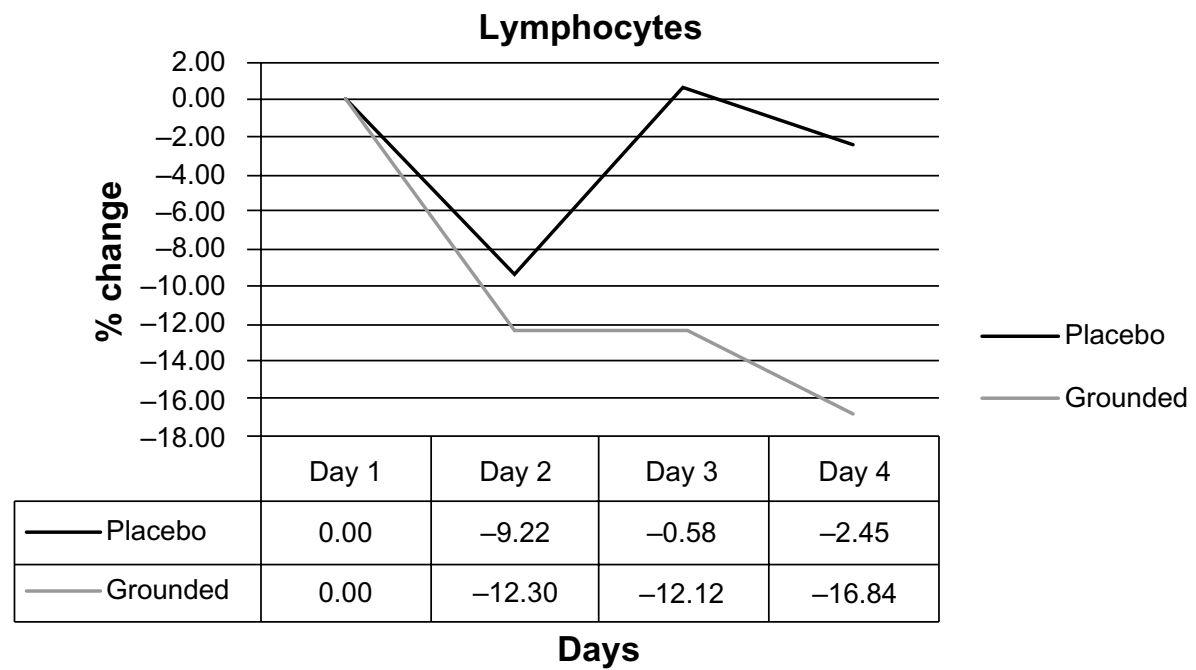

Figure 9 Comparisons of lymphocyte counts, pretest versus post-test for each group. 

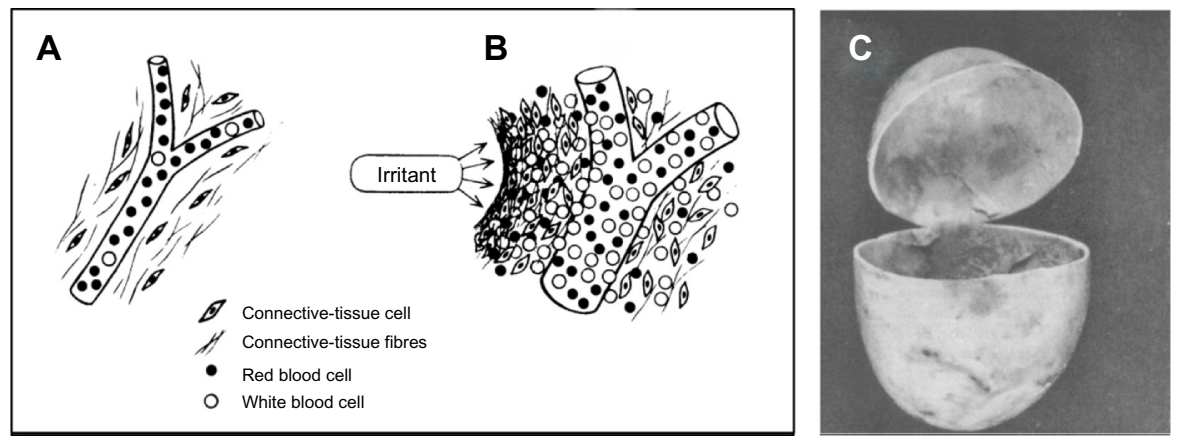

Figure 10 Formation of the inflammatory barricade.

Notes: Copyright (C) 1984, Selye H. Reproduced from Selye H. The Stress of Life. Revised ed. New York: McGraw-Hill Companies, Inc.; I984.25 (A) Normal connective tissue territory. (B) Same tissue after injury or exposure to irritant. Vessel dilates, blood cells migrate toward irritant, connective tissue cells and fibers form a thick impenetrable barricade that prevents the spread of the irritant into the blood, but that also inhibits entry of regenerative cells that could repair the tissue and slow the entry of antioxidants into the repair field. The result can be a long-lasting pocket of incompletely resolved inflammation that can eventually leak toxins into the system and disturb functioning of an organ or tissue. This is referred to as "silent" or "smoldering" inflammation. (C) The inflammatory, Selye, or granuloma pouch as originally described by Selye, ${ }^{30}$ is widely used in studies of inflammation.

body, on the mucosal membrane of the tongue, and in the venous blood rapidly drop to approximately $-200 \mathrm{mV}$. When the body is disconnected from the Earth, the potential is quickly restored. These effects reveal changes in the internal electrical environment within the body. ${ }^{29}$

Selye ${ }^{30}$ studied the histology of the wall of the inflammatory pouch or barricade (Figure 10). It is composed of fibrin and connective tissue. Our hypothesis is that electrons can be semi-conducted across the barrier, and can then neutralize reactive oxygen species (free radicals). ${ }^{30}$ A semiconducting collagen pathway or corridor may explain how electrons from the Earth quickly attenuate chronic inflammation not resolved by dietary antioxidants or by standard medical care, including physical therapy (Figure 3). The barricade probably restricts diffusion of circulating antioxidants into the repair.

Taken together, these observations indicate that grounding or earthing the human body significantly alters the inflammatory response to an injury.

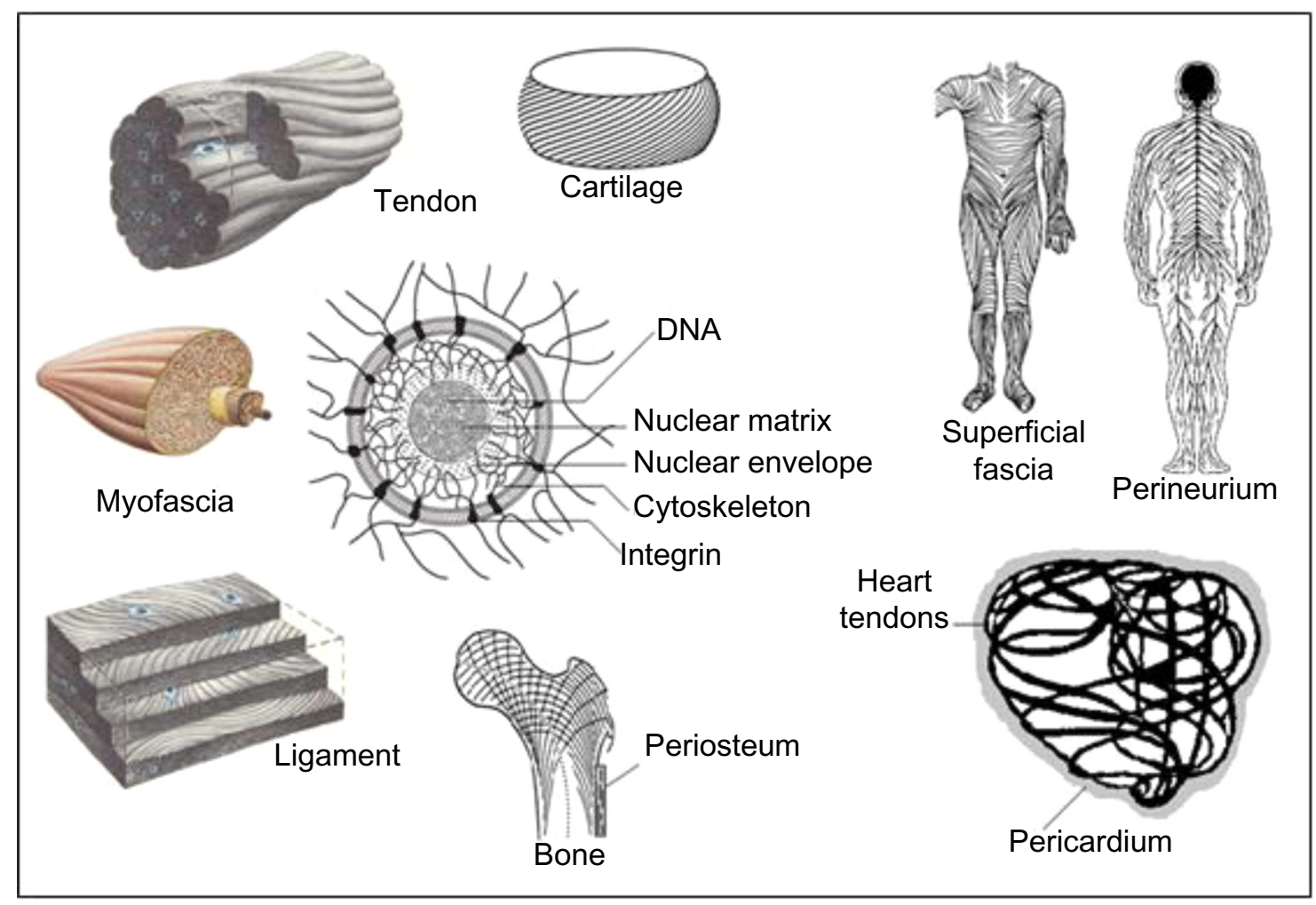

Figure I I The living matrix, ground regulation system, or tissue tensegrity matrix is a continuous fibrous web-work or network that extends into every part of the body. The extracellular components of this network consist primarily of collagen and ground substance. It is the largest system in the body, as it is the only system that touches all of the other systems. 
A

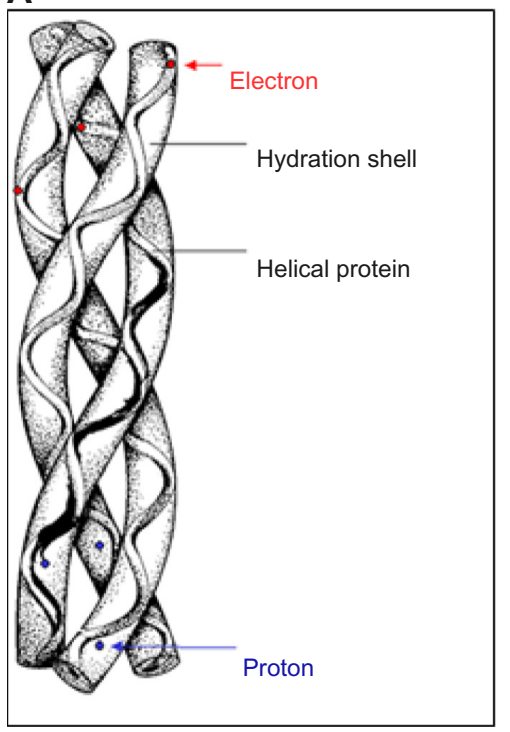

B

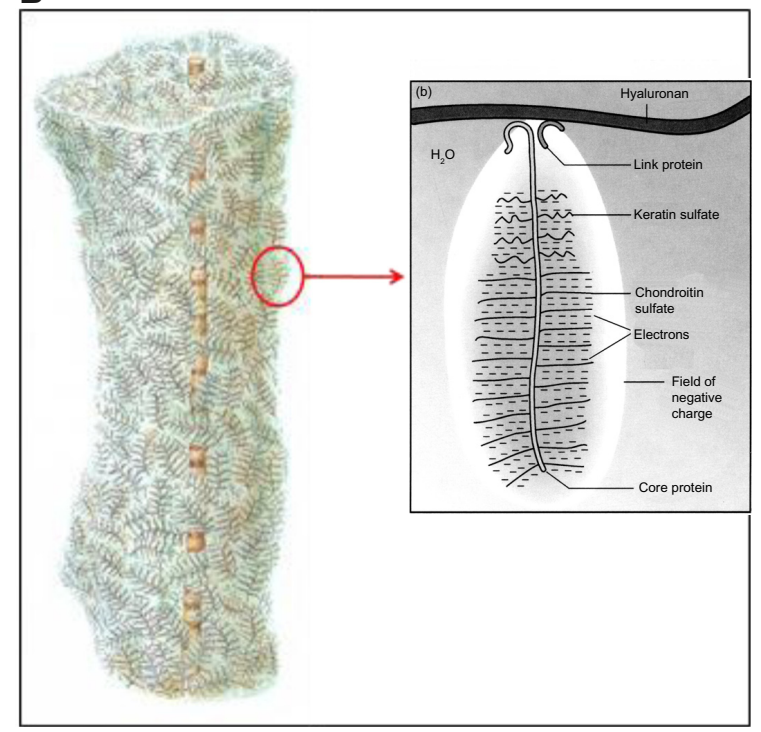

Figure 12 Collagen and ground substance.

Notes: (A) Collagen, the principal protein of the extracellular connective tissue matrix, is a triple helix with a hydration shell surrounding each polypeptide strand. The protein can transfer electrons by semiconduction, and protons $\left(\mathrm{H}^{+}\right)$and hydroxyls $\left(\mathrm{OH}^{-}\right)$migrate through the hydration shell. These charge movements can be very rapid and are vital to life. (B) Copyright @ 2005. R Paul Lee Reproduced with permission from Lee RP. Interface. Mechanisms of Spirit in Osteopathy. Portland, OR: Stillness Press; 2005. ${ }^{67}$ The ground substance is a highly charged polyelectrolyte gel, a vast reservoir of electrons. Note the collagen fibril embedded in ground substance units known as matrisomes (a term coined by Heine). ${ }^{33}$ Detail of a matrisome to the right (b) reveals vast stores of electrons. Electrons from the ground substance can migrate through the collagen network to any point in the body. We suggest that they can maintain an anti-oxidant microenvironment around an injury repair field, slowing or preventing reactive oxygen species delivered by the oxidative burst from causing collateral damage to healthy tissue, and preventing or reducing the formation of the so-called "inflammatory barricade".

\section{Anatomical and biophysical aspects}

The concept that the inflammatory barricade forms from collateral damage to healthy tissue surrounding an injury site is supported by Selye's classic studies published along with his description of the granuloma or Selye pouch (Figure 10). ${ }^{25,30}$ Moreover, research in cell biology and biophysics reveals the human body is equipped with a system-wide collagenous, liquid-crystalline semiconductor network known as the living matrix, ${ }^{31}$ or in other terms, a ground regulation system ${ }^{32,33}$ or tissue tensegrity matrix system (Figure 11). ${ }^{34}$ This bodywide network can deliver mobile electrons to any part of the body and thereby routinely protect all cells, tissues, and organs from oxidative stress or in the event of injury. ${ }^{23,31}$ The living matrix includes the extracellular and connective tissue matrices as well as the cytoskeletons of all cells. ${ }^{31}$ Integrins at cell surfaces are thought to allow for semi-conduction of electrons to the cell interior, and links across the nuclear envelope enable the nuclear matrix and genetic material to be part of the circuitry. ${ }^{23}$ Our hypothesis is that this body-wide electronic circuit represents a primary antioxidant defense system. This hypothesis is the central point of this report.

The extracellular part of the matrix system is composed mainly of collagen and ground substances (Figures 11 and 12). The cytoskeleton is composed of microtubules, microfilaments, and other fibrous proteins. The nuclear matrix contains another protein fabric composed of histones and related materials.

It is not widely appreciated that collagen and other structural proteins are semiconductors. This concept was introduced by Albert Szent-Györgyi in the Korányi memorial lecture in Budapest, Hungary in 1941. His talk was published in both Science (Towards a New Biochemistry?) ${ }^{35}$ and Nature (The Study of Energy Levels in Biochemistry). ${ }^{36}$ The idea that proteins might be semiconductors was immediately and firmly rejected by biochemists. Many modern scientists continue to reject semi-conduction in proteins, because living systems only have trace amounts of silicone, germanium, and compounds of gallium that are the most widely used materials in electronic semiconductor devices. However, there are many ways of making organic semiconductors without using metals. One of the sources of confusion was the widely held belief that water was a mere filler material. We now know that water plays crucial roles in enzymatic activities and semi-conduction. Hydrated proteins actually are semiconductors, and have become important components in the global microelectronics industry. Organic microcircuits are preferred for some applications, because they can be made very small, self-assemble, are robust, and have low energy consumption. ${ }^{37,38}$

One of the leaders in the field of molecular electronics, NS Hush, has recognized Albert Szent-Györgyi and 
Robert S Mulliken for providing two concepts fundamental to the industrial applications: theories of biological semiconduction, and molecular orbital theory, respectively. ${ }^{39}$ In recent studies, given awards by the Materials Research Society in both Europe and the USA, scientists from Israel made flexible biodegradable semiconductor systems using proteins from human blood, milk, and mucus. ${ }^{40}$ Silicon, the most widely used semiconducting material, is expensive in the pure form needed for semiconductors, and is inflexible and environmentally problematic. Organic semiconductors are predicted to lead to a new range of flexible and biodegradable computer screens, cell phones, tablets, biosensors, and microprocessor chips. We have come a long way since the early days when semi-conduction in proteins was so thoroughly rejected. ${ }^{41,42,43}$

Ground substance polyelectrolyte molecules associated with the collagenous connective tissue matrix are charge reservoirs (Figure 12). The matrix is therefore a vast whole-body redox system. The glycosaminoglycans have a high density of negative charges due to the sulfate and carboxylate groups on the uronic acid residues. The matrix is therefore a body-wide system capable of absorbing and donating electrons wherever they are needed to support immune functioning. ${ }^{44}$ The interiors of cells including the nuclear matrix and DNA are all parts of this biophysical electrical storage and delivery system. The time-course of the effects of grounding on injury repair can be estimated in various ways. First, we know from medical infrared imaging that inflammation begins to subside within 30 minutes of connecting with the earth via a conductive patch placed on the skin. ${ }^{2,3}$ Secondly, metabolic activity increases during this same period. Specifically, there is an increase in oxygen consumption, pulse rate, and respiratory rate and a decrease in blood oxygenation during 40 minutes of grounding. ${ }^{45} \mathrm{We}$ suspect that the "filling" of the charge reservoirs is a gradual process, possibly because of the enormous number of charged residues on the polyelectrolytes, and because they are located throughout the body. When charge reservoirs are saturated, the body is in a state we refer to as "inflammatory preparedness". This means that the ground substance, which pervades every part of the body, is ready to quickly deliver antioxidant electrons to any site of injury via the semiconducting collagenous matrix (see Figure 16B).

These considerations also imply anti-aging effects of earthing or grounding, since the dominant theory of aging emphasizes cumulative damage caused by ROS produced during normal metabolism or produced in response to pollutants, poisons, or injury. ${ }^{46}$ We hypothesize an anti-aging effect of grounding that is based on a living matrix reaching every part of the body and that is capable of delivering antioxidant electrons to sites where tissue integrity might be compromised by reactive oxidants from any source. ${ }^{47,48}$

Molecules generated during the immune response were also followed in the DOMS study. ${ }^{7}$ Parameters that differed consistently by $10 \%$ or more between grounded and ungrounded subjects, normalized to baseline, included creatine kinase, phosphocreatine/inorganic phosphate ratios, bilirubin, phosphorylcholine, and glycerolphosphorylcholine. Bilirubin is a natural antioxidant that helps control ROS. ${ }^{49-53}$ While bilirubin levels decreased in both grounded and ungrounded groups, the margin between the subjects was large (Figure 13). ${ }^{7}$

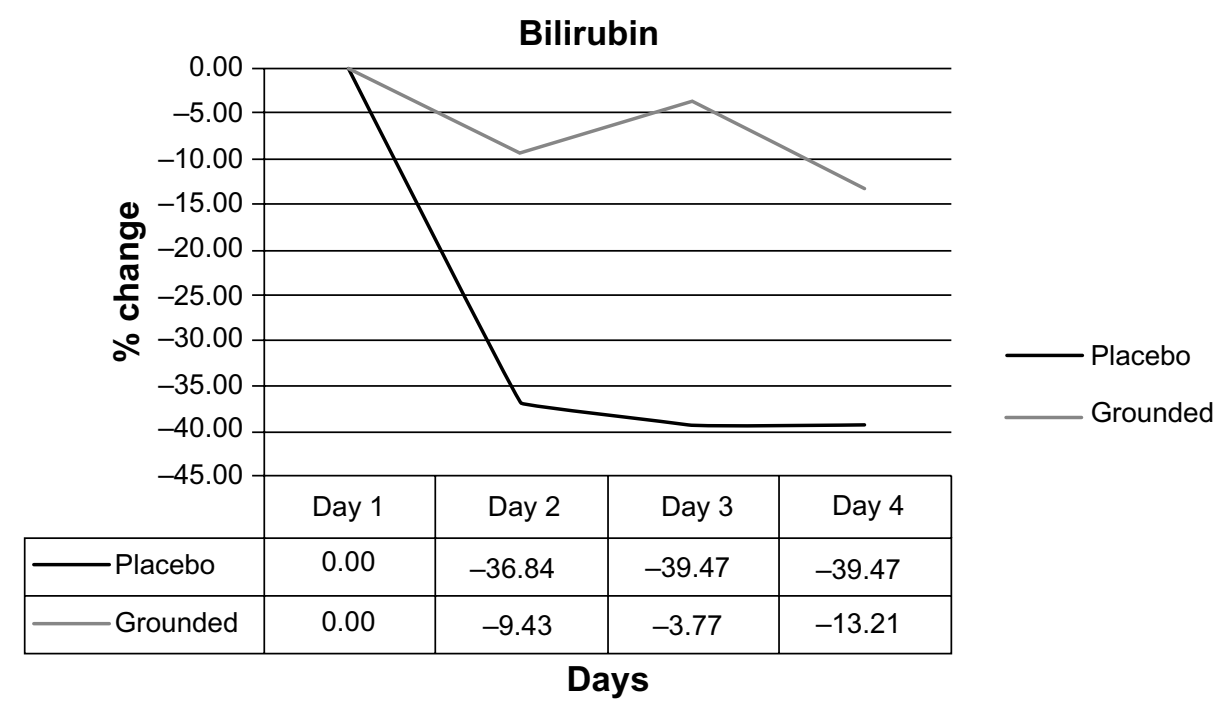

Figure 13 Comparisons of bilirubin levels, pretest versus post-test for each group. 


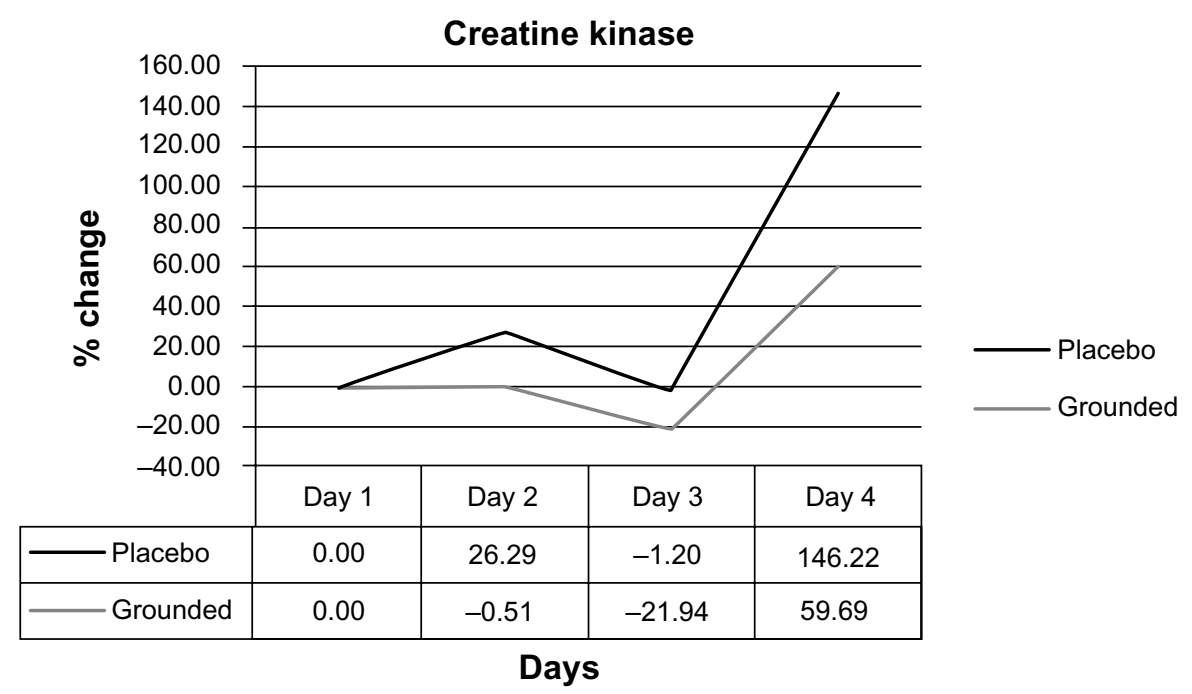

Figure 14 Creatine kinase levels, pretest versus post-test for each group.

The inflammatory markers changed at the same time that the pain indicators were changing. This was revealed by both the visual analog pain scale and by the pressure measurements on the right gastrocnemius (Figures 5 and 6). The authors of the DOMS study suggested that bilirubin may have been used as a source of electrons in the ungrounded subjects. ${ }^{7}$ It is possible that the lower decline in circulating bilirubin in the grounded subjects was due to the availability in the repair field of free electrons from the Earth.

Other markers encourage the hypothesis that the grounded subjects more efficiently resolved tissue damage: the pain measures, inorganic phosphate-phosphocreatine ratios $(\mathrm{Pi} /$ $\mathrm{PCr}$ ), and creatine kinase (CK). Muscle damage has been widely correlated with CK. ${ }^{54-56}$ As Figure 14 shows, CK values in the ungrounded subjects were consistently above those in the grounded subjects. ${ }^{7}$ Differences between $\mathrm{Pi} / \mathrm{PCr}$ of the two groups were monitored by magnetic resonance spectroscopy. These ratios are indicative of metabolic rate and cellular damage. ${ }^{57-60}$ Inorganic phosphate levels are indicative of hydrolysis of $\mathrm{PCr}$ and adenosine triphosphate. The ungrounded subjects had higher levels of $\mathrm{Pi}$, while the grounded subjects showed higher levels of PCr. These findings indicate that mitochondria in the grounded subjects are not producing as much metabolic energy, probably because there is less demand due to more rapid achievement of homeostasis. The differences between the groups are shown in Figure 15.

The pilot study ${ }^{7}$ on the effects of earthing in speeding recovery from the pain of DOMS provides a good basis for a larger study. The concepts presented here are summarized in Figure 16 as a comparison between "Mr Shoes"

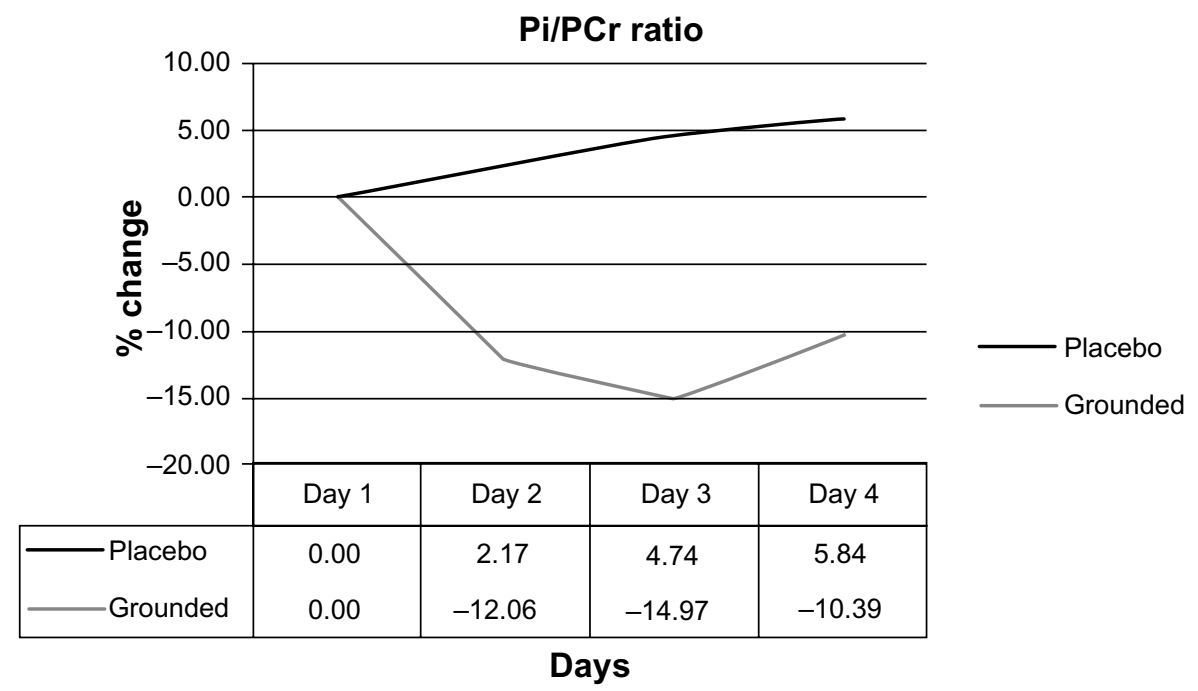

Figure 15 Inorganic phosphate/phosphocreatine ratios (Pi/PCr) pretest versus post-test for each group. 

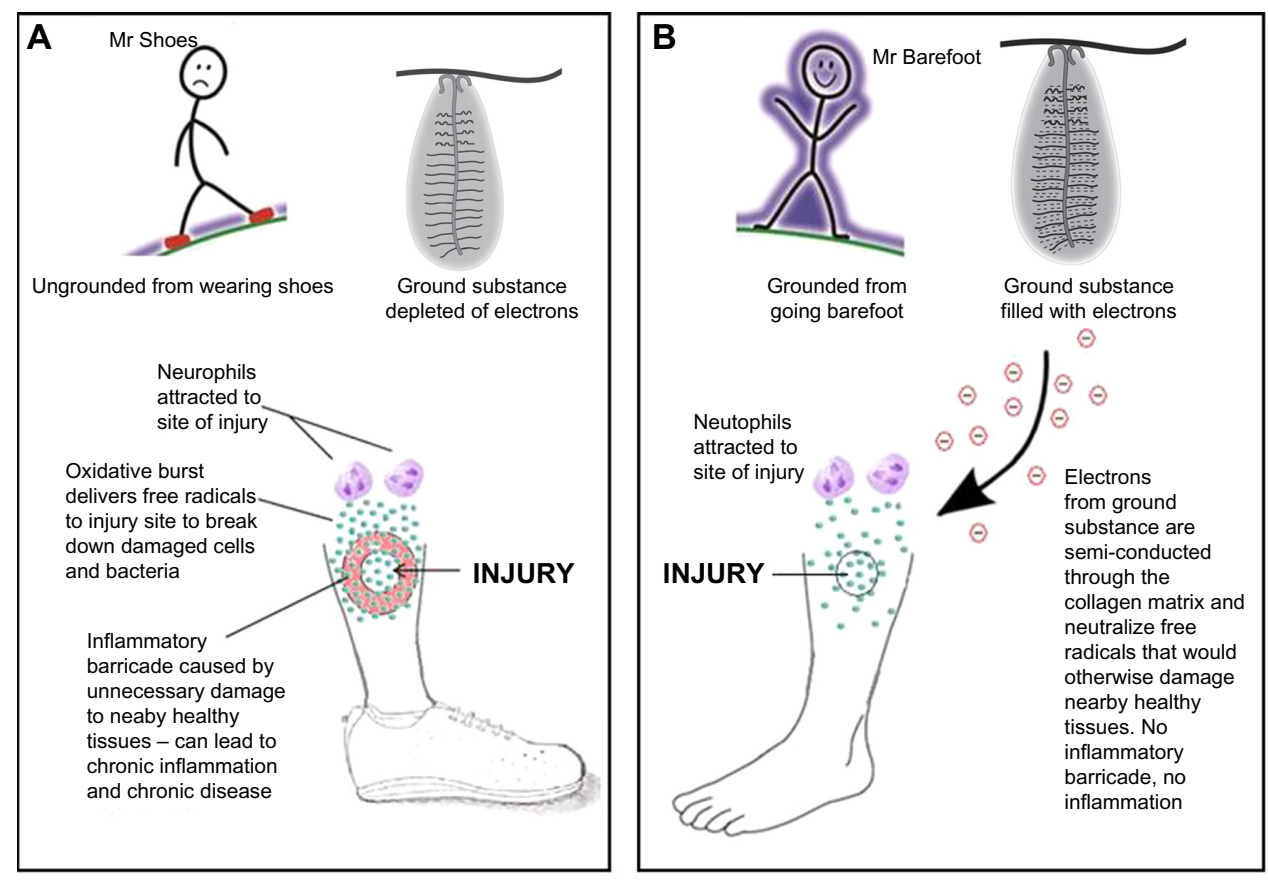

Figure 16 Summary of central hypothesis of this report: comparison of immune response in ungrounded versus grounded person.

Notes: (A) After an injury, the ungrounded person (Mr Shoes) will form an inflammatory barricade around the injury site. (B) After an injury, the grounded person (Mr Barefoot) will not form an inflammatory barricade, because reactive oxygen species that could damage nearby healthy tissue (collateral damage) are immediately neutralized by electrons semiconducted from the electron-saturated ground substance via the collagen network.

(an ungrounded individual) and "Mr Barefoot" (a grounded individual).

\section{Discussion}

Voluminous current research correlates inflammation with a wide range of chronic diseases. A search for "inflammation" in the National Library of Medicine database (PubMed) reveals over 400,000 studies, with more than 34,000 published in 2013 alone. The most common cause of death and disability in the United States is chronic disease. Seventy-five percent of the nation's health care spending, which surpassed US\$2.3 trillion in 2008, is for treating chronic disease. Heart disease, cancer, stroke, chronic obstructive pulmonary disease, osteoporosis, and diabetes are the most common and costly chronic diseases. ${ }^{61}$ Others include asthma, Alzheimer's disease, bowel disorders, cirrhosis of the liver, cystic fibrosis, multiple sclerosis, arthritis, lupus, meningitis, and psoriasis. Ten percent of all health care dollars are spent treating diabetes. Osteoporosis affects about 28 million aging Americans. ${ }^{61,62}$ However, there are few theories on the mechanisms connecting chronic inflammation with chronic disease. The research on grounding or earthing summarized here provides a logical and testable theory based on a variety of evidence.

The textbook description of the immune response describes how large or small injuries cause neutrophils and other white blood cells to deliver highly ROS and RNS to break down pathogens and damaged cells and tissues. Classical textbook descriptions also refer to an "inflammatory barricade" that isolates injured tissues to hinder the movement of pathogens and debris from the damaged region into adjacent, healthy tissues. Selye described how the debris coagulates to form the inflammatory barricade (Figure 10). This barrier also hinders the movements of antioxidants and regenerative cells into the blocked-off area. Repair can be incomplete, and this incomplete repair can set up a vicious inflammatory cycle that can persist for a long period of time, leading to so-called silent or smoldering inflammation that in turn, over time, can promote the development of chronic disease.

Remarkable as it may seem, our findings suggest that this classical picture of the inflammatory barricade may be a consequence of lack of grounding, and of a resultant "electron deficiency". Wounds heal very differently when the body is grounded (Figures 1 and 2). Healing is much faster, and the cardinal signs of inflammation are reduced or eliminated. The profiles of various inflammatory markers over time are very different in grounded individuals.

Those who research inflammation and wound healing need to be aware of the ways grounding can alter the time-course of inflammatory responses. They also need to be aware that the experimental animals they use for their studies may have 
very different immune systems and responses, depending on whether or not they were reared in grounded or ungrounded cages. It is standard research practice for investigators to carefully describe their methods and the strain of the animals they use so that others can repeat the studies if they wish. An assumption is that all Wistar rats, for example, will be genetically and physiologically similar. However, a comparison of neoplasms in Sprague-Dawley rats (originally outbred from the Wistar rat) from different sources revealed highly significant differences in the incidences of endocrine and mammary tumors. The frequency of adrenal medulla tumors also varied in rats from the same suppliers raised in different laboratories. The authors "stressed the need for extreme caution in evaluation of carcinogenicity studies conducted at different laboratories and/or on rats from different sources." ${ }^{33}$

From our perspective, these variations are not at all surprising. Animals will differ widely in the degree to which their charge reservoirs are saturated with electrons. Are their cages made of metal, and if they are, is that metal grounded? How close are their cages to wires or conduits carrying 60/50 $\mathrm{Hz}$ electricity? From our research, those factors will have measurable impacts on immune responses. In fact, they represent a "hidden variable" that could have affected the outcomes of countless studies, and also could affect the ability of other investigators to reproduce a particular study.

Dominant lifestyle factors such as insulating footwear, high-rise buildings, and elevated beds separate most humans from direct skin connection with the Earth's surface. An earth connection was an everyday reality in past cultures that used animal skins for footwear and to sleep on. We suggest that the process of killing pathogens and clearing debris from injury sites with ROS and RNS evolved to take advantage of the body's constant access to the virtually limitless source of mobile electrons the Earth provides when we are in contact with it. Antioxidants are electron donors, and the best electron donor, we strongly believe, is right under our feet: the surface of the Earth, with its virtually unlimited storehouse of accessible electrons. Electrons from the Earth may in fact be the best antioxidants, with zero negative secondary effects, because our body evolved to use them over eons of physical contact with the ground. Our immune systems work beautifully as long as electrons are available to balance the ROS and reactive nitrogen species (RNS) used when dealing with infection and tissue injury. Our modern lifestyle has taken the body and the immune system by surprise by suddenly depriving it of its primordial electron source. This planetary separation began accelerating in the early 1950s with the advent of shoes made with insulating soles instead of the traditional leather.
Lifestyle challenges to our immune systems proceeded faster than evolution could accommodate.

The disconnection from the Earth may be an important, insidious, and overlooked contribution to physiological dysfunction and to the alarming global rise in non-communicable, inflammatory-related chronic diseases. A lack of electrons can also de-saturate the electron transport chains in mitochondria, leading to chronic fatigue and slowing the cellular migrations and other essential activities of the cells of the immune system. ${ }^{64}$ At this point, even a minor injury can lead to a long-term health issue. When mobile electrons are not available, the inflammatory process takes an abnormal course. Areas that are electron deficient are vulnerable to further injury - they become positively charged and will have difficulty warding off infections. The result is an immune system constantly activated and eventually exhausted. Cells of the immune system may fail to distinguish between the body's diverse chemical structures (called "self") and the molecules of parasites, bacteria, fungi, and cancer cells (called "non-self"). This loss of immunologic memory can lead to attacks by some immune cells on the body's own tissues and organs. An example is the destruction of insulin-producing beta cells of the islets of Langerhans in the diabetic patient. Another example is the immune system attacking cartilage in joints, producing rheumatoid arthritis. Lupus erythematosus is an extreme example of an auto-immune condition caused by the body's immune system attacking host tissues and organs. Lupus, for example, can affect many different body systems, including skin, kidneys, blood cells, joints, heart, and lungs. With time, the immune system becomes weaker and the individual more vulnerable to inflammation or infections that may not heal, as often seen with the wounds of diabetic patients. Specifically, which part or parts of the body the weakened immune system will attack first depends on many factors such as genetics, habits (sleep, food, drinks, exercise, etc), and toxins in the body and in the environment. ${ }^{65,66}$ A repeated observation is that grounding, or earthing, reduces the pain in patients with lupus and other autoimmune disorders. ${ }^{1}$

\section{Conclusion}

Accumulating experiences and research on earthing, or grounding, point to the emergence of a simple, natural, and accessible health strategy against chronic inflammation, warranting the serious attention of clinicians and researchers. The living matrix (or ground regulation or tissue tensegrity-matrix system), the very fabric of the body, appears to serve as one of our primary antioxidant defense systems. As this report 
explains, it is a system requiring occasional recharging by conductive contact with the Earth's surface - the "battery" for all planetary life - to be optimally effective.

\section{Acknowledgments}

The authors are indebted to Martin Zucker for very valuable comments on the manuscript. A Clinton Ober of EarthFx Inc. has provided continuous support and encouragement for the research that has been done to explore the science of earthing, with particular focus on the immune system.

\section{Disclosure}

G Chevalier and JL Oschman are independent contractors for EarthFx Inc., the company sponsoring earthing research, and own a small percentage of shares in the company. Richard Brown is an independent contractor for EarthFx Inc., the company sponsoring earthing research. The authors report no other conflicts of interest.

\section{References}

1. Ober CA, Sinatra ST, Zucker M. Earthing: The Most Important Health Discovery Ever? 2nd ed. Laguna Beach: Basic Health Publications; 2014.

2. Amalu W. Medical thermography case studies. Clinical earthing application in 20 case studies [undated article on the Internet]. Available from: http://74.63.154.231/here/wp-content/uploads/2013/06/Amalu_thermographic_case_studies_2004.pdf. Accessed July 5, 2008.

3. Oschman JL. Can Electrons act as antioxidants? A review and commentary. J Altern Complement Med. 2007;13:955-967.

4. Chevalier G, Sinatra ST, Oschman JL, Sokal K, Sokal P. Review article: Earthing: health implications of reconnecting the human body to the Earth's surface electrons. J Environ Public Health; 2012;2012: 291541.

5. Ghaly M, Teplitz, D. The biologic effects of grounding the human body during sleep as measured by cortisol levels and subjective reporting of sleep, pain, and stress. J Altern Complement Med. 2004;10(5): 767-776.

6. Cohen S, Janicki-Deverts D, Doyle WJ, et al. Chronic stress, glucocorticoid receptor resistance, inflammation, and disease risk. Proc Natl Acad Sci U S A. 2012;109(16):5995-5999.

7. Brown D, Chevalier G, Hill M. Pilot study on the effect of grounding on delayed-onset muscle soreness. JAltern Complement Med. 2010;16(3): 265-273.

8. Butterfield TA, Best TM, Merrick MA. The dual roles of neutrophils and macrophages in inflammation: a critical balance between tissue damage and repair. J Athl Train. 2006;41(4):457-465.

9. Takmakidis SP, Kokkinidis EA, Similios I, Douda H. The effects of ibuprofen on delayed onset muscle soreness and muscular performance after eccentric exercise. J Strength Cond Res. 2003;17(1):53-59.

10. Close GL, Ashton T, Cable T, Doran D, MacLaren DP. Eccentric exercise, isokinetic muscle torque and delayed onset muscle soreness: the role of reactive oxygen species. Eur J Appl Physiol. 2004;91(5-6): 615-621.

11. MacIntyre DL, Reid WD, Lyster DM, Szasz IJ, McKenzie DC. Presence of WBC, decreased strength, and delayed soreness in muscle after eccentric exercise. J Appl Physiol (1985). 1996;80(3):1006-1013.

12. Franklin ME, Currier D, Franklin RC. The effect of one session of muscle soreness inducing weight lifting exercise on WBC count, serum creatine kinase, and plasma volume. J Orthop Sports Phys Ther. 1991;13(6):316-321.
13. Peake J, Nosaka K, Suzuki K. Characterization of inflammatory responses to eccentric exercise in humans. Exerc Immunol Rev. 2005;11: 64-85.

14. MacIntyre DL, Reid WD, McKenzie DC. Delayed muscle soreness: the inflammatory response to muscle injury and its clinical implications. Sports Med. 1995;20(1):24-40.

15. Smith LL, Bond JA, Holbert D, et al. Differential white cell count after two bouts of downhill running. Int J Sports Med. 1998;19(6): 432-437.

16. Smith LL. Cytokine hypothesis of overtraining: a physiological adaptation to excessive stress? Med Sci Sports Exerc. 2000;32(2):317-331.

17. Ascensão A, Rebello A, Oliveira E, Marques F, Pereira L, Magalhães J. Biochemical impact of a soccer match: analysis of oxidative stress and muscle damage throughout recovery. Clin Biochem. 2008;41(10-11): 841-851.

18. Smith LL, McCammon M, Smith S, Chamness M, Israel RG, O’Brien KF. White blood cell response to uphill walking and downhill jogging at similar metabolic loads. Eur J Appl Physiol. 1989;58(8):833-837.

19. Broadbent S, Rousseau JJ, Thorp RM, Choate SL, Jackson FS, Rowlands DS. Vibration therapy reduces plasma IL6 and muscle soreness after downhill running. Br J Sports Med. 2010;44(12): 888-894.

20. Gleeson M, Almey J, Brooks S, Cave R, Lewis A, Griffiths H. Haematological and acute-phase responses associated with delayed-onset muscle soreness. Eur J Appl Physiol Occup Physiol. 1995;71(2-3): $137-142$.

21. Tidball JG. Inflammatory processes in muscle injury and repair. $A m J$ Physiol Regul Integr Comp Physiol. 2005;288(2):R345-R353.

22. Zhang J, Clement D, Taunton J. The efficacy of Farabloc, an electromagnetic shield, in attenuating delayed-onset muscle soreness. Clin J Sport Med. 2000;10(1):15-21.

23. Oschman JL. Charge transfer in the living matrix. J Bodyw Mov Ther. 2009;13(3):215-228.

24. Best TM, Hunter KD. Muscle injury and repair. Phys Med Rehabil Clin North Am. 2000;11(2):251-266.

25. Selye H. The Stress of Life. Revised ed. New York: McGraw-Hill Companies, Inc.; 1984.

26. Motoyama H. Measurements of Ki energy: Diagnoses and Treatments. Tokyo: Human Science Press, 1997.

27. Colbert AP, Yun J, Larsen A, Edinger T, Gregory WL, Thong T. Skin impedance measurements for acupuncture research: development of a continuous recording system. Evid Based Complement Altern Med. 2008;5(4):443-450.

28. Reichmanis M, Marino AA, Becker RO. Electrical correlates of acupuncture points. IEEETrans Biomed Eng. 1975;22(6):533-535.

29. Sokal K, Sokal P. Earthing the human organism influences bioelectrical processes. J Altern Complement Med. 2012;18(3):229-234.

30. Selye H. On the mechanism through which hydrocortisone affects the resistance of tissues to injury; an experimental study with the granuloma pouch technique. JAMA. 1953;152(13):1207-1213.

31. Oschman JL, Oschman NH. Matter, energy, and the living matrix. Rolf Lines. 1993;21(3):55-64.

32. Pischinger A. The Extracellular Matrix and Ground Regulation: Basis for a Holistic Biological Medicine. Berkeley: North Atlantic Books; 2007.

33. Heine H. Lehrbuch der biologischen Medizin. Grundregulation und Extrazellulare Matrix. [Handbook of Biological Medicine. The extracellular matrix and ground regulation]. Stuttgart: Hippokrates Verlag; 2007. German.

34. Pienta KJ, Coffey DS. Cellular harmonic information transfer through a tissue tensegrity-matrix system. Med Hypotheses. 1991;34(1): 88-95.

35. Szent-Györgyi A. Towards a new biochemistry? Science. 1941;93: 609-611.

36. Szent-Györgyi A. The study of energy levels in biochemistry. Nature. 1941;148(3745):157-159.

37. Tokita Y. Proteins as semiconductor devices [article on the Internet]. Available from: http://www.jsst.jp/e/JSST2012/extended_abstract/ pdf/16.pdf. Accessed May 23, 2014. 
38. Sarpeshkar R. Ultra Low Power Bioelectronics. Fundamentals, Biomedical Applications, and Bio-inspired Systems. Cambridge: Cambridge University Press; 2010.

39. Hush NS. An overview of the first half-century of molecular electronics. Ann NY Acad Sci. 2003;1006:1-20.

40. Mentovich E, Belgorodsky B, Gozin M, Richter S, Cohen H. Doped biomolecules in miniaturized electric junctions. J Am Chem Soc. 2012;134(20):8468-8473.

41. Cuevas JC, Scheer E. Molecular Electronics: An Introduction to Theory and Experiment. Singapore; World Scientific Series in Nanoscience and Nanotechnology, Volume 1; World Scientific Publishing Co. Singapore. 2010.

42. Reimers JR, United Engineering Foundation (US); et al. Molecular electronics III. New York, NY; Annals of the New York Academy of Sciences; 1006; 2003.

43. Joachim C, Ratner MA. Molecular electronics: Some views on transport junctions and beyond. Proc Natl Acad Sci. USA. 2005;102(25): 8801-8808.

44. Heine H. Homotoxicology and Ground Regulation System (GRS). Baden-Baden: Aurelia-Verlag; 2000.

45. Chevalier G. Changes in pulse rate, respiratory rate, blood oxygenation, perfusion index, skin conductance, and their variability induced during and after grounding human subjects for 40 minutes. J Altern Complement Med. 2010;16(1): 81-87.

46. Miwa S, Beckman KB, Muller FL, editors. Oxidative Stress in Aging: From Model Systems to Human Diseases. Totowa: Humana Press; 2008.

47. Oschman JL. 2008. Mitochondria and cellular aging. In: Klatz R, Goldman R, editors. Anti-Aging Therapeutics. Volume XI. Chicago: American Academy of Anti-Aging Medicine; 2009:275-287.

48. Kessler WD, Oschman JL. Counteracting aging with basic physics. In: Klatz R, Goldman R, editors. Anti-Aging Therapeutics. Volume XI. Chicago: American Academy of Anti-Aging Medicine; 2009:185-194.

49. Stocker R. Antioxidant activities of bile pigments. Antioxid Redox Signal. 2004;6(5):841-849.

50. Paschalis V, Nikolaidis MG, Fatouros IG, et al. Uniform and prolonged changes in blood oxidative stress after muscle-damaging exercise. In Vivo. 2007;21(5):877-883.

51. Nikolaidis MG, Paschalis V, Giakas G, et al. Decreased blood oxidative stress after repeated muscle damaging exercise. Med Sci Sports Exerc. 2007;39(7):1080-1089.

52. Florczyk UM, Jozkowicz A, Dulak J. Biliverdin reductase: new features of an old enzyme and its potential therapeutic significance. Pharmacol Rep. 2008;60(1):38-48.
53. Sedlak TW, Salehb M, Higginson DS, Paul BD, Juluri KR, Snyder SH. Bilirubin and glutathione have complementary antioxidant and cytoprotective roles. Proc Natl Acad Sci U S A. 2009;106(13):5171-5176.

54. Close GL, Ashton T, McArdle A, MacLaren DP. The emerging role of free radicals in delayed onset muscle soreness and contractioninduced muscle injury. Comp Biochem Physiol A Mol Integr Physiol. 2005; 142(3):257-266.

55. Hirose L, Nosaka K, Newton M, et al. Changes in inflammatory mediators following eccentric exercise of the elbow flexors. Exerc Immunol Rev. 2004;10:75-90.

56. Hartmann U, Mester J. Training and overtraining markers in selected sport events. Med Sci Sports Exerc. 2000;32(1):209-215.

57. McCully KK, Argov Z, Boden BP, Brown RL, Bank WJ, Chance B. Detection of muscle injury in humans with 31-P magnetic resonance spectroscopy. Muscle Nerve. 1988;11(3):212-216.

58. McCully KK, Posner J. Measuring exercise-induced adaptations and injury with magnetic resonance spectroscopy. Int J Sports Med. 1992;13(S1):S147-S149.

59. McCully KK, Shellock FG, Bank WJ, Posner JD. The use of nuclear magnetic resonance to evaluate muscle injury. Med Sci Sports Exerc. 1992;24(5):537-542.

60. Zehnder M, Muelli M, Buchli R, Kuehne G, Boutellier U. Further glycogen decrease during early recovery after eccentric exercise despite a high carbohydrate intake. Eur J Nutr. 2004;43(3):148-159.

61. Swartz K. Projected Costs of Chronic Diseases. Health Care Cost Monitor. The Hastings Center; 2011. Available from: http://healthcarecostmonitor.thehastingscenter.org/kimberly Swartz/projected-costs-ofchronic-diseases/. Accessed January18, 2011.

62. Partnership to Fight Chronic Disease. Available from: http://www.fightchronicdisease.org/issues/about.cfm. Accessed January 18, 2011.

63. Mac Kenzie WF, Garner FM. Comparison of neoplasms in six sources of rats. J Natl Cancer Inst. 1973;50(5):1243-1257.

64. Oschman JL. Mitochondria and cellular aging. Anti-Aging Therapeutics Volume XI, Klatz R Goldman R. eds; Chicago IL; in American Academy of Anti-Aging Medicine, 2008;285-287.

65. Biagi E, Candela M, Fairweather-Tait S, Franceschi C, Brigidi P. Aging of the human metaorganism: the microbial counterpart. Age (Dordr). 2012;34(1):247-267.

66. Franceschi C, Bonafè M, Valensin S, et al. Inflamm-aging. An evolutionary perspective on immunosenescence. Ann N Y Acad Sci. 2000;908:244-254.

67. Lee RP. Interface. Mechanisms of Spirit in Osteopathy. Portland, OR: Stillness Press; 2005.
Journal of Inflammation Research

\section{Publish your work in this journal}

The Journal of Inflammation Research is an international, peer-reviewed open-access journal that welcomes laboratory and clinical findings on the molecular basis, cell biology and pharmacology of inflammation including original research, reviews, symposium reports, hypothesis formation and commentaries on: acute/chronic inflammation; mediators of inflamma-

\section{Dovepress}

tion; cellular processes; molecular mechanisms; pharmacology and novel anti-inflammatory drugs; clinical conditions involving inflammation. The manuscript management system is completely online and includes a very quick and fair peer-review system. Visit http://www.dovepress.com/ testimonials.php to read real quotes from published authors. 